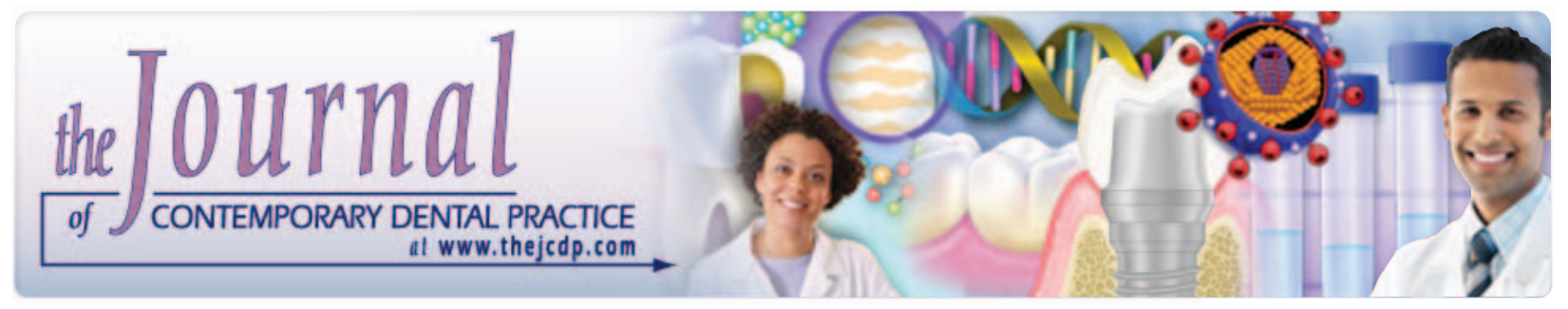

\title{
Smear Layer Removal for Collagen Fiber Exposure after Citric Acid Conditionings
}

Rodrigo Cavassim, ${ }^{*}$ DDS, MSc; Fábio Renato Manzolli Leite, DDS, MSc; Daniela Leal Zandim, DDS, MSc; Andrea Abi Rached Dantas, DDS, MSc; José Eduardo Cezar Sampaio, DDS, PhD

\section{Abstract}

Aim: The aim of the present study was to compare the removal of the smear layer and exposure of collagen fibers of the root surface following the application of five citric acid solution concentrations.

Methods and Materials: Two hundred seventy (270) samples were equally divided into six groups $(n=45)$ for treatment with saline solution (control) and five different concentrations of citric acid $(0.5,1,2,15$, and 25 percent). Three acid application methods were used (passive, brushing, and burnishing) as well as three application periods (1,2, and 3 minutes). A previously trained, calibrated (kappa score $=0.93$ ), and blind examiner subsequently scored scanning electron micrographs (SEMs) of the samples. Statistical analyses were performed by using Kruskal-Wallis and Dunn's post-hoc tests.

Results: According to the results obtained and within the limitations of the methodology used, the citric acid applications were more effective than the control treatment of applying saline solution $(p<0.05)$. However, no statistically significant differences were observed among the three application methods and three application periods. Descriptive analyses showed that best results for exposure of collagen fibers were obtained with the application of citric acid at 25 percent by brushing for 1 or 3 minutes.

Conclusions: The best results for exposure of collagen fibers in this study were obtained with application of citric acid at 25 percent by brushing

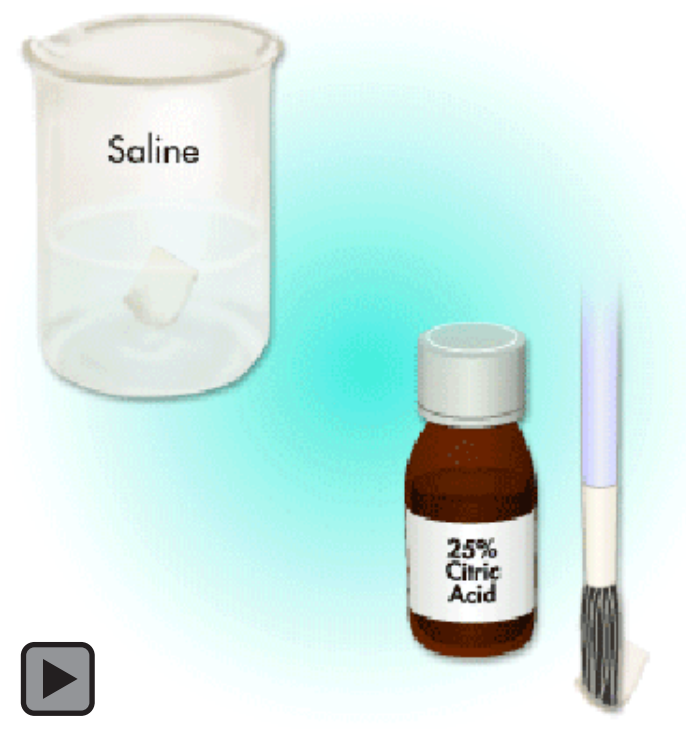

for 1 or 3 minutes, even though there were no statistically significant differences among the groups.

Clinical Significance: The best results for exposure of collagen fibers on root surfaces noted in this study were obtained with application of citric acid at 25 percent by brushing for 1 or 3 minutes.

Keywords: Acid conditioning collagen fibers, citric acid, laboratory study, root surfaces, smear layer

Citation: Cavassim R, Leite FRM, Zandim DL, Dantas AAR, Sampaio JEC. Smear Layer Removal for Collagen Fiber Exposure after Citric Acid Conditionings. J Contemp Dent Pract [Internet]. 
2010 December; 11(6):001-008. Available from: http://www.thejcdp.com/journal/view/volume11issue6-cavassim

*Submitted in partial fulfillment of the requirements for the Master of Science (MSc) degree from the Universidade Estadual Paulista (Unesp), Faculty of Dentistry.

\section{Introduction}

Periodontal therapy is intended to eliminate periodontal disease, restore periodontal tissues to a healthy and functional state, and ensure the subsequent maintenance of these tissues in that healthy state. Literature has clearly demonstrated that current modes of periodontal therapy are successful in achieving these goals. However, success in periodontal therapy not only seeks to arrest periodontal disease but also to achieve predictable regeneration of the periodontium at the sites of the previous breakdown. ${ }^{1-4}$

Treatment of periodontal disease by mechanical scaling and root planning produces a smear layer on the root surface that can impair healing and soft tissue regeneration. $\frac{5-7}{}$ To address this situation, substances can be applied to the root surface to remove the smear layer and expose collagen fibers in the dentin matrix..$^{2.8,9}$ One such substance capable of removing the smear layer and opening dentinal tubules is citric acid. $\frac{10-13}{\text { In }}$ addition, citric acid also can be used with other regenerative techniques to optimize results, enhancing periodontal regeneration. $\frac{14-18}{}$ However, citric acid's low pH may induce cytotoxic effects when in direct contact with periodontal cells. ${ }^{19}$

It has been shown that citric acid produces more clot stabilization on the dentin surface than tetracycline hydrochloride, ethylenediaminetetraacetic acid (EDTA), sodium citrate, or a saline solution..$^{20}$

Despite the ability of citric acid to promote root demineralization and to remove the smear layer, studies have not achieved a consensus for the parameters of the citric acid application, which has resulted in different reported outcomes. ${ }^{2.12,13,21-23}$ Therefore, the objective of this in vitro study was to evaluate smear layer removal and exposure of collagen fibers using scanning electron microscopy (SEM) after citric acid application on root surfaces to determine the most effective acid concentration and application method.

\section{Methods and Materials}

This study was approved by the Research Ethics Committee of Araraquara Dentistry SchoolUNESP-Brazil (protocol \# 31/06). A total of 135 teeth were obtained from the Human Tooth Bank of the institution. These teeth had no evidence of dental caries, restorations below the cementoenamel junction (CEJ), or any other cervical root lesions.

\section{Sample Preparation}

The cervical third of roots was chosen for the sample preparation. Samples were prepared by making two parallel grooves, approximately 0.5 $\mathrm{mm}$ wide, on the buccal and lingual root surfaces of each tooth using a high-speed cylindrical diamond bur (KG Sorensen, Barueri, SP, Brazil) under copious water irrigation. The first groove was made horizontally at the cementoenamel junction, and the second groove was made approximately 3 $\mathrm{mm}$ from the first in the apical direction. The same bur was used to remove the surface layer of the root between the two grooves (Figure 1). The area between the two grooves was then scaled with 50 apical-cervical strokes using a sharp \# 5-6 Gracey curette (Hu-Friedy, Chicago, IL, USA) (Figure 2).

Two samples were obtained from each tooth and all of them were stored in containers with saline solution.

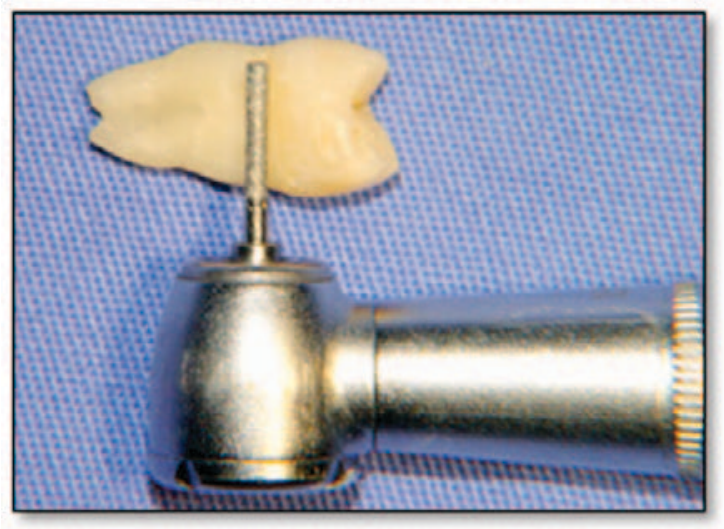

Figure 1. Preparation of the first groove at the CEJ and the second groove placed $3 \mathrm{~mm}$ apical from the first. After groove preparation, the surface layer of the root between the grooves was removed with the same bur. 
Two hundred seventy dentin samples, approximately $3 \times 4 \times 1 \mathrm{~mm}$ in size, were obtained and randomly divided into five experimental groups ( $\mathrm{n}=45$ for each group) and one control group (Figure 3).

The control group was conditioned with saline solution and the experimental groups were conditioned with different citric acid

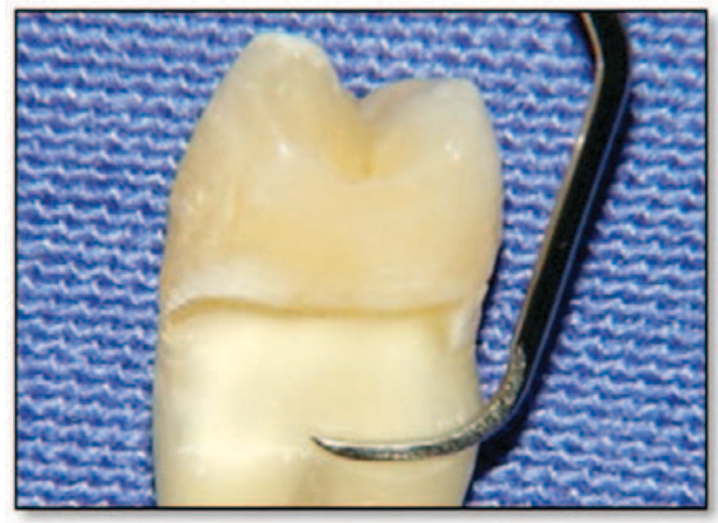

Figure 2. Fifty apical-cervical scraping strokes made on the area between the two grooves with the curette. concentrations $(0.5,1,2,15$, or 25 percent). These six groups were further divided into three subgroups (15 samples each) according to the application method of the solutions used. There were also three application methods used: (1) passive application with a small, cotton pellet; (2) brushing application with a soft brush; and (3) burnishing application with a small, cotton pellet. Each of these three subgroups was further divided into three application periods of 1,2 , or 3 minutes with 5 samples in each subgroup.

During each application period, solutions were renewed on the cotton pellet or brush every 30 seconds. A new pellet or brush was used for each solution. Thereafter each sample was rinsed with $10 \mathrm{ml}$ of saline solution and identified with a code for blind scoring of the SEMs.

All samples were then dehydrated in an increasingly graded series of alcohols $(30,50$, $70,80,95$, and 100 percent) for 1 hour each. After immersion in the 100 percent ethanol concentration, samples were placed in a 50 percent $(\mathrm{v} / \mathrm{v})$ solution of 100 percent ethanol and
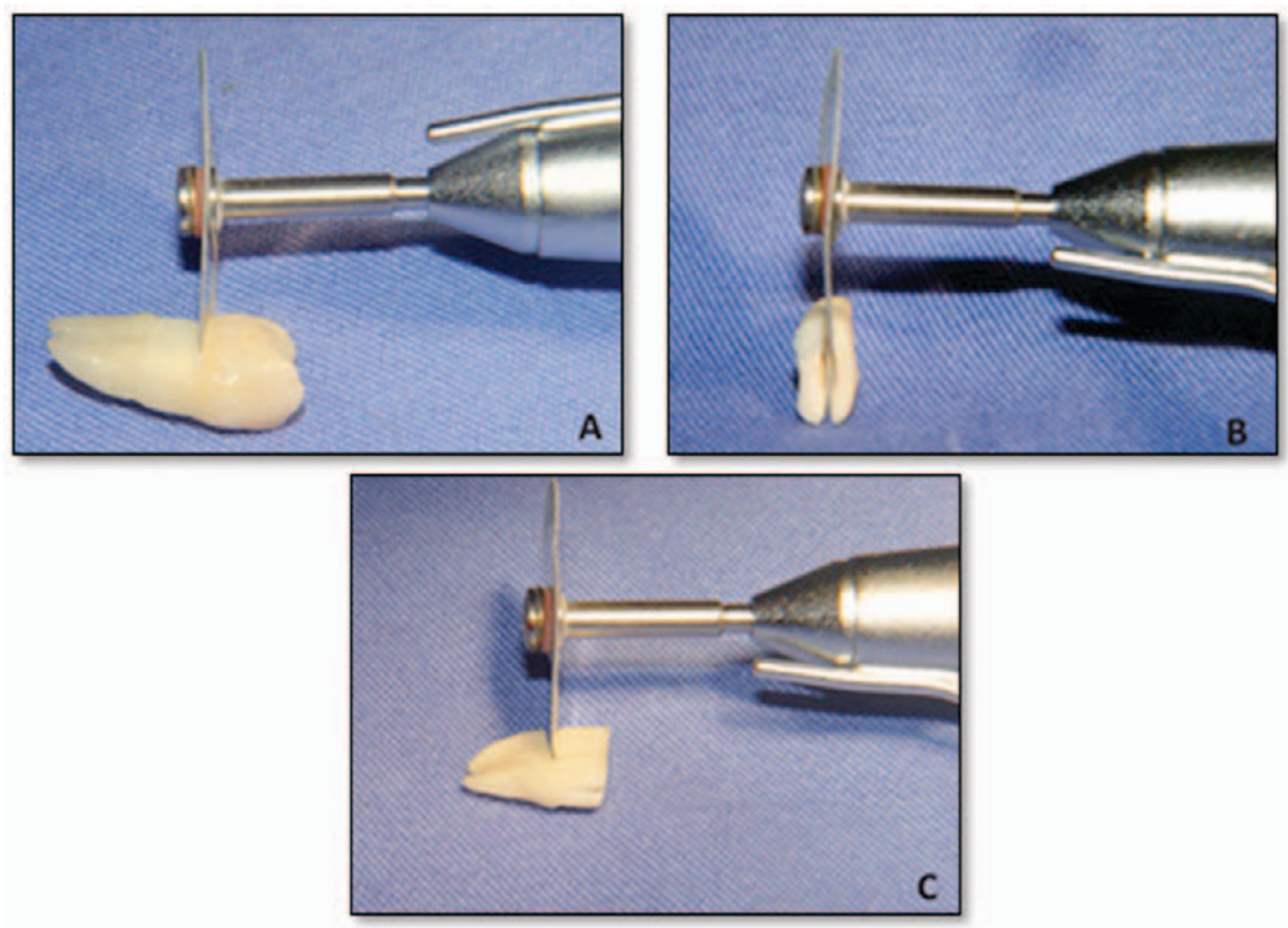

Figure 3. Sample preparation procedure. (A) The dental crown above the first groove was removed. (B) Then a longitudinal cut was made in the central part of the tooth. (C) Finally, a horizontal cut was made to produce the samples. 
hexamethyldisilazane (HMDS) (Sigma, SigmaAldrich Inc., St. Louis, MO, USA) for 30 minutes with a final immersion in 100 percent HMDS for 10 minutes. Finally, samples were dried overnight in a dehydration jar (Corning, Sao Paulo, SP, Brazil), mounted on metallic stubs (Senai, Sao Paulo, SP, Brazil), and sputter-coated with a thin $25 \mathrm{~nm}$ layer of 99.99 percent pure gold.

\section{SEM Analysis}

Two photomicrographs were obtained from the center area of each sample under 1,500X and $3,500 \mathrm{X}$ magnifications, using a scanning electron microscope operated at an accelerating voltage of $20 \mathrm{kV}$ (Jeol T330 A, Jeol Ltd., Peabody, MA, USA). The photomicrographs were scored according to a root surface modification index (Figure 4) adapted for this study. ${ }^{\underline{24}}$ Three evaluations at 15-day intervals were performed by one previously calibrated and experienced examiner. The examiner was blind to the experimental groups. The final score actually recorded for each sample was the most prevalent score among the three evaluations. The scoring criteria for the adapted root modification index used for this study consisted of eight scores, ranging from 1 to 8 , as shown in Figure 4. Good reproducibility was achieved for use of the index with a weighted kappa score of 0.93 .

\section{Statistical Analysis}

The nonparametric analysis of variance (KruskalWallis test) was applied to independently evaluate the effect of the three dependent variables, solution concentration, application mode, and application period, at a 5 percent significance level. If a $p$ value was $\leq 0.05$, Dunn's Multiple Comparison post-hoc test was applied to detect statistically significant differences among the groups. The statistical analyses were performed with the GraphPad Prism 5.00 software (San Diego, CA, USA).

\section{Results}

Citric acid demineralization produced a variety of surface topographies. The surface appearance ranged from a rough amorphous surface with no evidence of fiber material to a surface made up of collagen fibers, best described as a "shag carpet" appearance of tufted fibers. Samples that exhibited exposure of collagen fibers and opening of dentinal tubules corresponded to concentrations of 1, 15, and 25 percent (Figure 5).

Partial opening of dentinal tubules were observed in all citric acid concentrations and in the control group. Traces of debris were observed in the openings of dentinal tubules at concentrations of $0.5,1$, and 2 percent, and in two samples of the control group. A high frequency of chemical dissolution was observed for all citric acid concentrations evaluated as well as for samples in the control group. Kruskall-Wallis test analysis of variance showed significant differences among groups $(p<0.0001)$. Dunn's post-hoc test showed that significant differences appeared when comparing the control group to all other groups $(p<0.05)$. However, no statistically significant differences were found among the five citric acid solutions of the experimental groups.

There also were no statistically significant differences observed among the three application periods $(p=0.0793)$. Nevertheless, high frequencies of collagen fiber exposure (Score 1) were observed in the application period of three minutes (eight samples) followed by the application period of one minute (seven samples) of citric acid solutions (Figure 6).

Analysis of the effect of the application methods did not find any significant differences among groups ( $p=0.8525$ ); however, the highest frequency of collagen fibers exposure was observed for the brushing application method (14 samples) (Figure 7).

\section{Discussion}

The results of this study showed that scaling and root planing produced a smear layer that was removed from the root surface by a citric acid application. The smear layer itself is comprised of very small particles of organic and inorganic material. $\stackrel{6,25,26}{ }$ These particles vary in size from less than $1 \mu \mathrm{m}$ to more than $15 \mu \mathrm{m}$, and the layer is in intimate contact with the tooth surface and only removed by applying a demineralizing solution. $\frac{25,27}{}$ Studies have suggested that this smear layer, interposed between the root surface and adjacent connective tissue, may act as a physical barrier for the development of a connective tissue attachment to the root surface. ${ }^{?}$ On the other 

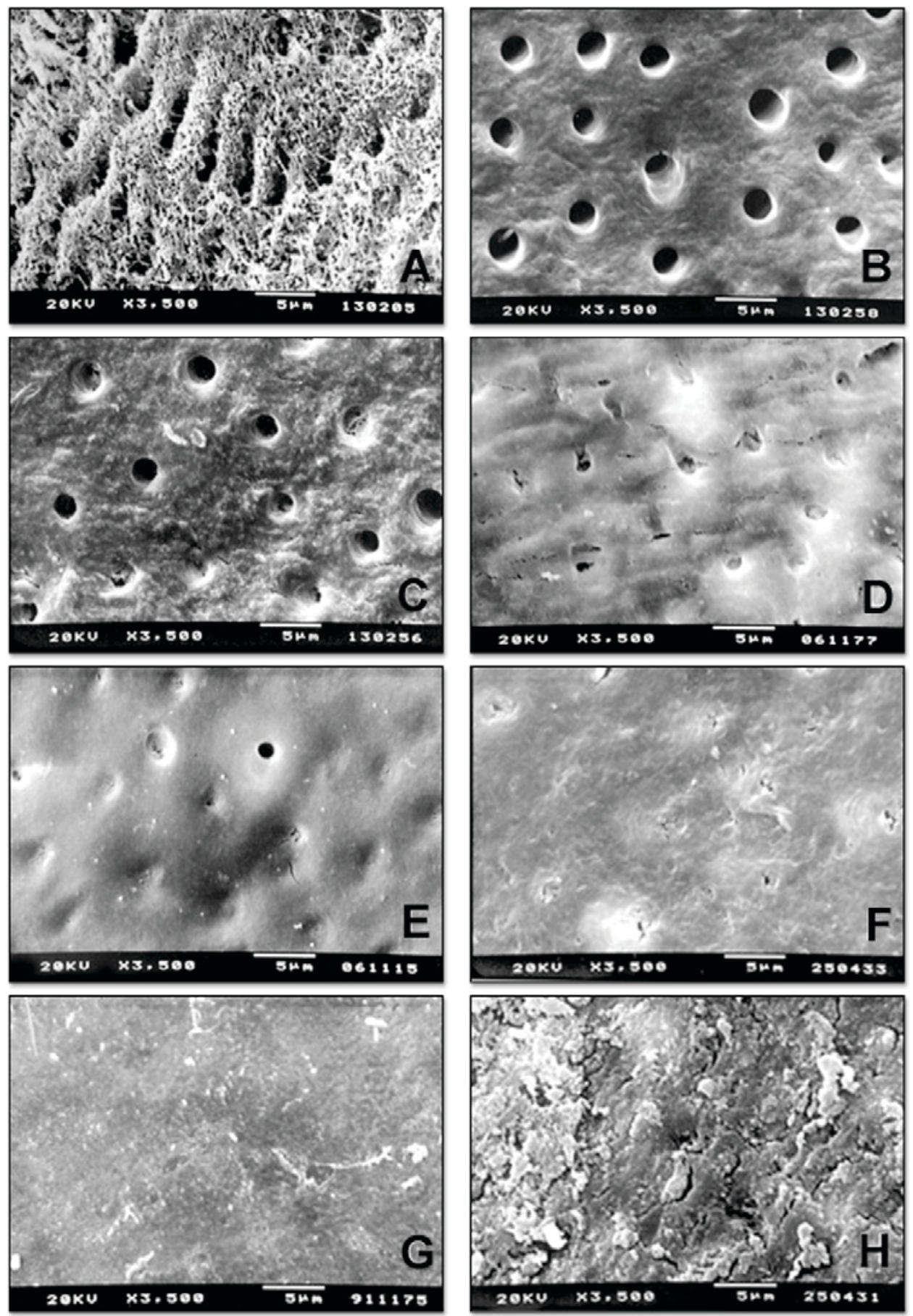

Figure 4. Evaluation criteria used in the adapted root modification index. (A) Score 1. Complete smear layer removal with dentin collagen fibers exposure. Complete opened dentin tubules, without a trace of the smear layer on the root surface. (B) Score 2. Complete smear layer removal but no collagen fibers exposure. Complete opened dentin tubules. (C) Score 3. Traces of smear layer remaining in the openings of dentinal tubules. (D) Score 4. Partial opening of the dentinal tubules. (E) Score 5. Smear layer formed by chemical dissolution of the dentin surface covering the root surface. $(F)$ Score 6. Uniform smear layer covering the dentin surface with some signs of tubule openings. (G) Score 7. Dentin surface covered by a uniform smear layer with no signs of dentinal tubule opening. (H) Score 8. Rough smear layer covering the dentinal surface. 


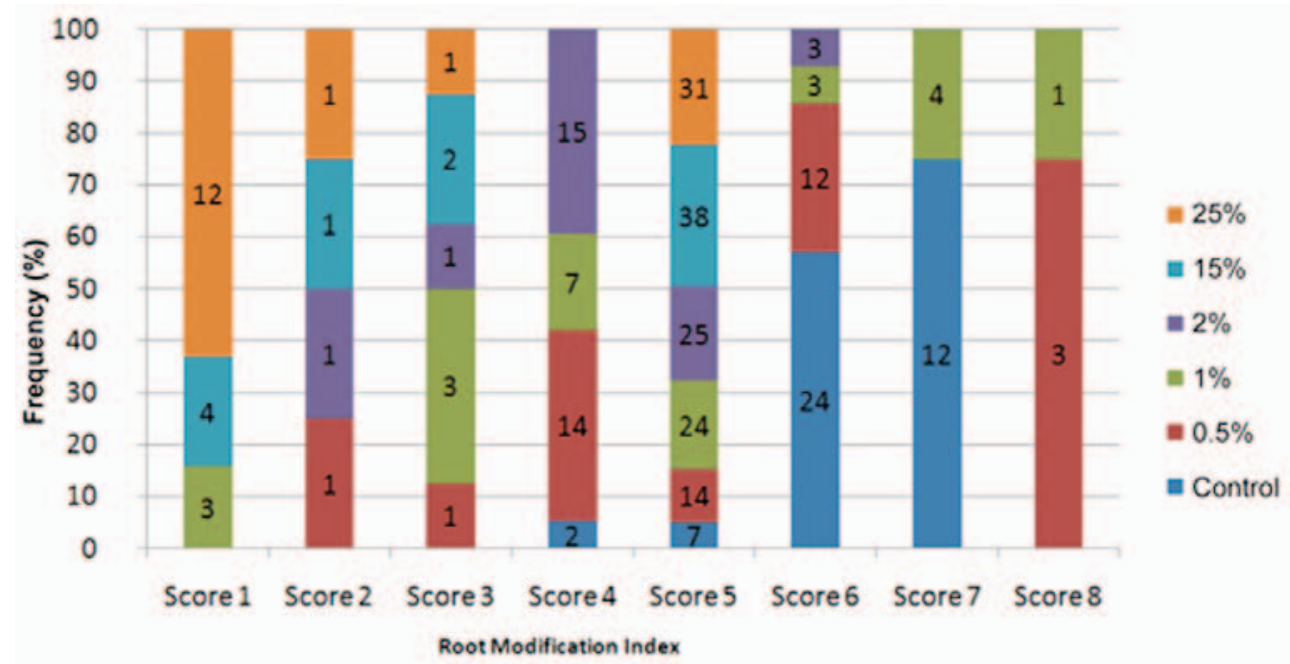

Figure 5. Frequency of concentrations 25, 15, 2, 1, 0.5 percent, and the controls in the scores of root surface modification.

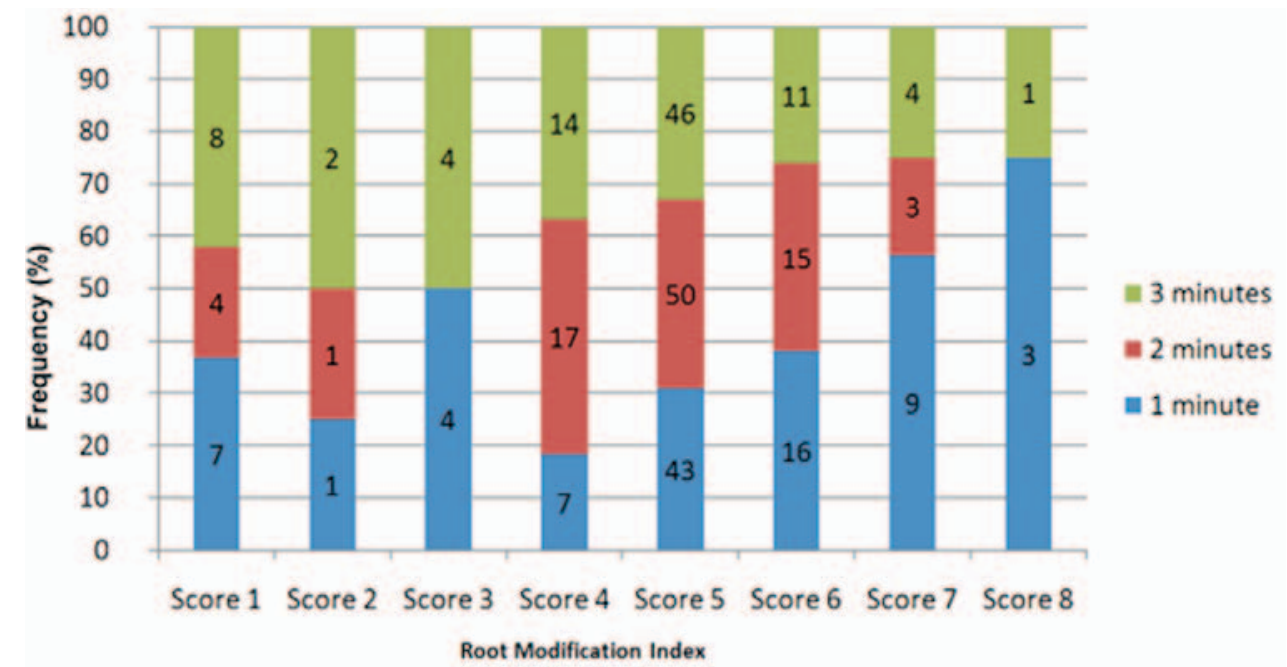

Figure 6. Frequency of 1-, 2-, and 3-minute application periods in the scores of root surface modification.

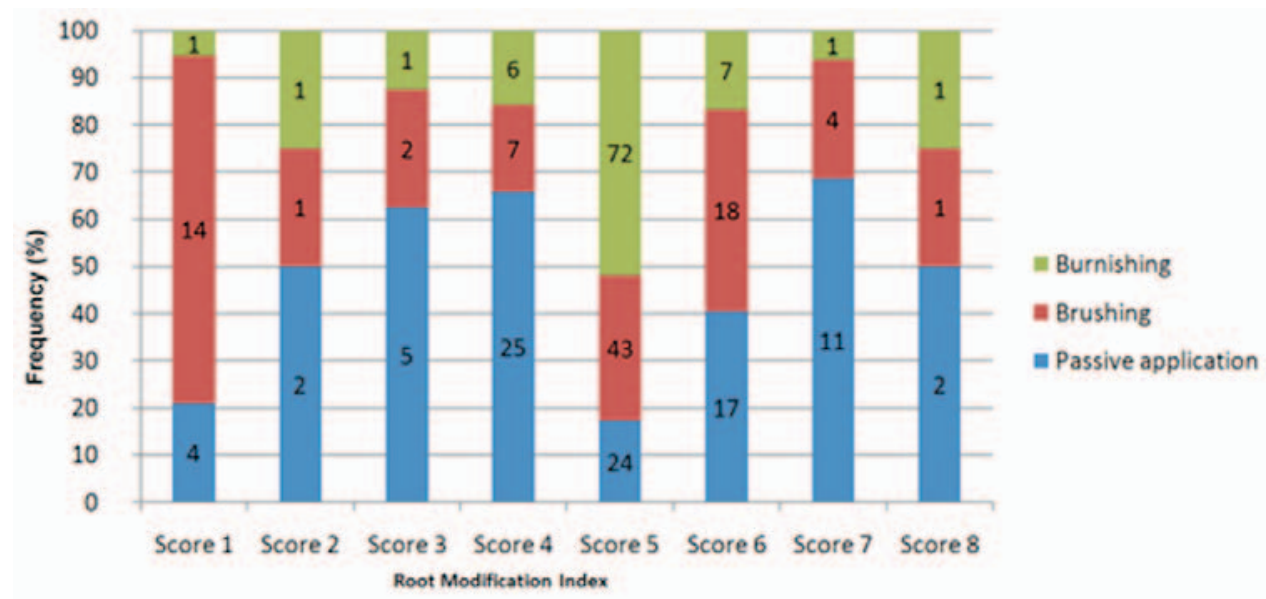

Figure 7. Frequency of passive, brushing, and burnishing applications in the scores of root surface modification. 
hand, the collagenous matrix, exposed by the use of demineralizing substances, appears to offer a more "hospitable" environment for cell attachment ${ }^{4}$ and may predispose the root to a new connective tissue attachment. $\frac{3,14-16,22,28}{}$

After evaluating the effects of citric acid concentrations and the parameters of the three application methods and three application periods, variability was noted in the scoring results obtained. All five of the experimental groups exhibited significant differences from the control group. However, there were no significant differences in scores recorded for the five citric acid concentrations.

Despite the lack of significant differences, exposure of collagen fibers was obtained with concentrations of 1,15 , and 25 percent. Thus, the discussion of the results focuses on these three specific concentrations (Figure 5).

It was evident that 25 percent citric acid tended to produce more samples with collagen fiber exposure than either the 1 percent or 15 percent group (Table 1). These results are consist with those from other studies that reported the optimum dentin demineralization was obtained with citric acid solution concentration between 25 and 30 percent..$^{23,29}$

Although statistical analysis of the application period effects indicated that there were no significant differences among groups, application for one minute as well as three minutes promoted demineralization of dentin and exposure of collagen fibers in a higher frequency than the two-minute application (Figure 6). These results also are in agreement with Codelli et al., ${ }^{21}$ who showed that complete demineralization could be achieved in three minutes with a burnishing action, compared to partial demineralization after three minutes with nonburnished (passive) action. Furthermore, five minutes of burnishing actually tended to result in excessive demineralization.

Furthermore, the results of the present study showed that the application of citric acid using the brushing technique tended to produce better results. Despite the lack of significant differences, brushing resulted in a higher frequency of samples with exposure of collagen fibers (Score 1), whereas burnishing tended to produce a higher number of samples that exhibited excessively demineralized surfaces (Score 5) (Figure 7).

Excessive demineralization seems to occur as a result of chemical and mechanical dissolution of the inorganic hydroxyapatite. The results of this study suggest that excessive demineralization is associated with the burnishing technique, as illustrated in Figure 7. Excessive demineralization of the dentin surface also raises the question of the biological acceptability of the resulting surface. Studies have suggested that a collagenous root surface, devoid of surface debris, offers a higher number of biological mechanisms by which new connective tissue attachment formation can be accelerated. $\frac{1,2,13,22,28}{2}$ These mechanisms include collagen splicing, mesenchymal cell induction, fibronectin adhesion, and fibroblast attachment. Studies have shown that demineralized dentin surfaces have a greater capacity to bind fibronectin than surfaces that did not undergo demineralization. $\frac{30,31}{}$ Apparently this increase

Table 1. Sample distribution for the citric acid concentrations that produced a score of 1 according to the root surface modification index.

\begin{tabular}{|c|c|c|c|c|}
\hline & & $1 \%$ & $15 \%$ & $25 \%$ \\
\hline \multirow{10}{*}{$\begin{array}{l}\text { Number of } \\
\text { samples }(n) \text { and } \\
\text { percentage (\%) }\end{array}$} & \multicolumn{4}{|c|}{ Citric Acid Concentrations } \\
\hline & & $3(100)$ & $4(100)$ & $12(100)$ \\
\hline & \multicolumn{4}{|c|}{ Application Methods } \\
\hline & Passive & 0 & $3(75)$ & $1(8.33)$ \\
\hline & Brushing & $3(100)$ & $1(25)$ & $10(83.33)$ \\
\hline & Burnishing & 0 & 0 & $1(8.33)$ \\
\hline & \multicolumn{4}{|c|}{ Application Periods } \\
\hline & 1 minute & $3(100)$ & 0 & $4(33.33)$ \\
\hline & 2 minutes & 0 & $2(50)$ & $2(16.67)$ \\
\hline & 3 minutes & 0 & $2(50)$ & $6(50)$ \\
\hline
\end{tabular}


in binding is due to exposure of more fibronectin binding sites on the collagen matrix. This change may increase the total number of binding sites available for proteins such as fibronectin, which in turn may help stabilize a mucoperiosteal flap during the initial stages of wound healing. ${ }^{\frac{32-34}{}}$

One aspect of this study, which differs from studies, is the use of hexamethyldisilazane. While other researchers ${ }^{1,7,11-13,21}$ used the critical-point drying with $\mathrm{CO}_{2}$ to prepare samples for SEM, here hexamethyldisilazane was used to dehydrate the samples. This method allows visualization of the collagen matrix in the SEM by preserving the microporosity of the dentin collagen fibers and actually preventing the exposed fibers from collapsing. ${ }^{35-38}$

The use of citric acid as a conditioning agent is supported by the literature and its advantages compared to other conditioning agents is supported by evaluation of blood cell adhesion ${ }^{20}$ and by human fibroblast adherence and proliferation to dentin surfaces. ${ }^{39}$

Certainly, other methods can be used to evaluate the effect of the citric acid conditioning and to verify how the results of this study can help the periodontal treatment. These include evaluation of fibroblast behavior on chemically conditioned dentin, ${ }^{39}$ evaluation of blood cell adhesion to dentin-conditioned surfaces, $\stackrel{20}{ }$ quantification of the parts per million (ppm) of calcium removed after conditioning, ${ }^{29}$ and immunohistochemical/ immunocytochemical analysis of the exposed collagen after conditioning. $\frac{32-34}{}$

Considerable variability in results may be seen among the various studies. Several factors, such as scaling details (hand scaling vs. piezoelectric scaling), could negatively interfere with the amount of residual calculus and root surface roughness. ${ }^{40-42}$ There are other considerations when selecting a substance for root conditioning because the outcome also may be influenced by the

- application period, application method, concentration, and $\mathrm{pH}$ of the substance used; $;$

- dilution and inactivation of substances when in contact with blood during surgical procedures; ${ }^{24}$

- preparation of samples and the storage medium, as well as a high degree of mineralization of the teeth; and
- pressure applied during the application process itself.

In addition, characteristics of the conditioning substance and a lack of a universal root modification index also may contribute to the reporting of varying results in the literature. For these reasons, we believe that exposure of collagen fibers by means of root conditioning is difficult to obtain as explained by the extensive variability and conflicting results found in the dental literature.

\section{Conclusion}

According to the results obtained in this study and within the limitations of the methodology used, it can be inferred that despite the lack of statistical significance, the best results for exposure of collagen fibers were obtained with application of citric acid at 25 percent by brushing for one or three minutes.

These results may contribute to the interpretation of other investigations found in the literature, for the design of in vivo studies on root conditioning, and for the clinical application of citric acid root conditioning in both periodontal treatment and regenerative procedures in order to optimize results. However, additional studies are recommended to support or refute these findings.

\section{Clinical Significance}

The best results for exposure of collagen fibers on root surfaces noted in this study were obtained with application of citric acid at 25 percent by brushing for one or three minutes.

\section{References}

1. Garrett JS, Crigger M, Egelberg J. Effects of citric acid on diseased root surfaces. J Periodontal Res. 1978; 13(2):155-63.

2. Register AA, Burdick FA. Accelerated reattachment with cementogenesis to dentin, demineralized in situ. I. Optimum range. J Periodontol. 1975; 46(11):646-55.

3. Register AA, Burdick FA. Accelerated reattachment with cementogenesis to dentin, 
demineralized in situ. II. Defect repair. J Periodontol. 1976; 47(9):497-505.

4. Stahl SS. Repair potential of the soft tissue-root interface. J Periodontol. 1977; 48(9):545-52.

5. Blomlöf JP, Blomlöf LB, Lindskog SF. Smear layer formed by different root planing modalities and its removal by an ethylenediaminetetraacetic acid gel preparation. Int J Periodontics Restorative Dent. 1997; 17(3):242-9.

6. Eick JD, Wilko RA, Anderson $\mathrm{CH}$, Sorensen SE. Scanning electron microscopy of cut tooth surfaces and identification of debris by use of the electron microprobe. J Dent Res. 1970; 49(6):Suppl:1359-68.

7. Polson AM, Frederick GT, Ladenheim S, Hanes PJ. The production of a root surface smear layer by instrumentation and its removal by citric acid. J Periodontol. 1984; 55(8):443-6.

8. Boyko GA, Brunette DM, Melcher AH. Cell attachment to demineralized root surfaces in vitro. J Periodontal Res. 1980; 15(3):297-303.

9. Ishi EP, Dantas AA, Batista LH, Onofre MA, Sampaio JE. Smear layer removal and collagen fiber exposure using tetracycline hydrochloride conditioning. J Contemp Dent Pract. 2008; 9(5):25-33.

10. Lafferty TA, Gher ME, Gray JL. Comparative SEM study on the effect of acid etching with tetracycline $\mathrm{HCl}$ or citric acid on instrumented periodontally-involved human root surfaces. J Periodontol. 1993; 64(8):689-93.

11. Sterrett JD, Bain C. Citric acid burnishing of dentinal root surfaces. A preliminary scanning electron microscopy report. J Can Dent Assoc. 1987; 53(5):395-7.

12. Sterrett JD, Dhillon M, Murphy HJ. Citric acid demineralization of cementum and dentin: the effect of application pressure. J Clin Periodontol. 1995; 22(6):434-41.

13. Sterrett JD, Murphy HJ. Citric acid burnishing of dentinal root surfaces. A scanning electron microscopy report. J Clin Periodontol. 1989; 16(2):98-104.

14. Albair WB, Cobb CM, Killoy WJ. Connective tissue attachment to periodontally diseased roots after citric acid demineralization. J Periodontol. 1982; 53(8):515-26.

15. Cole RT, Crigger M, Bogle G, Egelberg J, Selvig KA. Connective tissue regeneration to periodontally diseased teeth. A histological study. J Periodontal Res. 1980; 15(1):1-9.

16. Crigger M, Bogle G, Nilvéus R, Egelberg J, Selvig KA. The effect of topical citric acid application on the healing of experimental furcation defects in dogs. J Periodontal Res. 1978; 13(6):538-49.

17. Froum SJ, Kushner L, Stahl SS. Healing responses of human intraosseous lesions following the use of debridement, grafting and citric acid root treatment. I. Clinical and histologic observations six months postsurgery. J Periodontol. 1983; 54(2):67-76.

18. Stahl SS, Froum SJ, Kushner L. Healing responses of human intraosseous lesions following the use of debridement, grafting and citric acid root treatment. II. Clinical and histologic observations: one year postsurgery. J Periodontol. 1983; 54(6):325-38.

19. Lan WC, Lan WH, Chan CP, Hsieh CC, Chang MC, Jeng $\mathrm{JH}$. The effects of extracellular citric acid acidosis on the viability, cellular adhesion capacity and protein synthesis of cultured human gingival fibroblasts. Aust Dent J. 1999; 44(2):123-30.

20. Leite FR, Sampaio JE, Zandim DL, Dantas $A A$, Leite ER, Leite AA. Influence of rootsurface conditioning with acid and chelating agents on clot stabilization. Quintessence Int. 2010; 41(4):341-9.

21. Codelli GR, Fry HR, Davis JW. Burnished versus nonburnished application of citric acid to human diseased root surfaces: the effect of time and method of application. Quintessence Int. 1991; 22(4):277-83.

22. Polson AM, Proye MP. Effect of root surface alterations on periodontal healing. II. Citric acid treatment of the denuded root. J Clin Periodontol. 1982; 9(6):441-54.

23. Sterrett JD, Bankey T, Murphy HJ. Dentin demineralization. The effects of citric acid concentration and application time. J Clin Periodontol. 1993; 20(5):366-70.

24. Sampaio JE, Theodoro LH, Correa MA, Mendes AJ. A comparative SEM study of smear layer removal by detergents and EDTA on the root surface. Int J Periodontics Restorative Dent. 2005; 25(2):157-63.

25. Brännström M, Johnson G. Effects of various conditioners and cleaning agents on prepared dentin surfaces: a scanning electron microscopic investigation. J Prosthet Dent. 1974; 31(4):422-30.

26. Michelich VJ, Schuster GS, Pashley DH. Bacterial penetration of human dentin in vitro. J Dent Res. 1980; 59(8):1398-403.

27. Leidal TI, Eriksen HM. A scanning electron microscopic study of the effect of various 
cleansing agents on cavity walls in vitro.

Scand J Dent Res. 1979; 87(6):443-9.

28. Polson AM, Proye MP. Fibrin linkage: a precursor for new attachment. J Periodontol. 1983; 54(3):141-7.

29. Sterrett JD, Delaney B, Rizkalla A, Hawkins $\mathrm{CH}$. Optimal citric acid concentration for dentinal demineralization. Quintessence Int. 1991; 22(5):371-5.

30. Fernyhough W, Page RC. Attachment, growth and synthesis by human gingival fibroblasts on demineralized or fibronectin-treated normal and diseased tooth roots.

J Periodontol. 1983; 54(3):133-40.

31. Karp W, Sodek J, Aubin JE, Melcher AH. A comparison of fibronectin and laminin binding to undemineralized and demineralized tooth root surfaces. J Periodontal Res. 1986; 21(1):30-8.

32. Breschi L, Gobbi P, Lopes M, Prati C, Falconi M, Teti G, Mazzotti G. Immunocytochemical analysis of dentin: a double-labeling technique. J Biomed Mater Res A. 2003; 67(1):11-7.

33. Breschi L, Perdigão J, Gobbi P, Mazzotti G, Falconi M, Lopes M. Immunocytochemical identification of type I collagen in acidetched dentin. J Biomed Mater Res A. 2003; 66(4):764-9.

34. Ruggeri A Jr, Prati C, Mazzoni A, Nucci C, Di Lenarda R, Mazzotti G, Breschi L. Effects of citric acid and EDTA conditioning on exposed root dentin: An immunohistochemical analysis of collagen and proteoglycans. Arch Oral Biol. 2007; 52(1):1-8.

35. Bray DF, Bagu J, Koegler P. Comparison of hexamethyldisilazane (HMDS), Peldri II, and critical-point drying methods for scanning electron microscopy of biological specimens. Microsc Res Tech. 1993; 26(6):489-95.

36. Gusnard D, Kirschner RH. Cell and organelle shrinkage during preparation for scanning electron microscopy: effects of fixation, dehydration and critical point drying.

J Microsc. 1977; 110(1):51-7.

37. Nation JL. A new method using hexamethyldisilazane for preparation of soft insect tissues for scanning electron microscopy. Stain Technol. 1983; 58(6):347-51.

38. Perdigao J, Lambrechts $P$, Van Meerbeek B, Vanherle G, Lopes AL. Field emission SEM comparison of four postfixation drying techniques for human dentin. J Biomed Mater Res. 1995; 29(9):1111-20.
39. Rompen EH, Goffinet GH, Nusgens B. Human periodontal ligament fibroblast behavior on chemically conditioned dentine: an in vitro study. J Periodontol. 1999; 70(10):1144-52.

40. Hunter RK, O'Leary TJ, Kafrawy AH. The effectiveness of hand versus ultrasonic instrumentation in open flap root planing. J Periodontol. 1984; 55(12):697-703.

41. Jacobson L, Blomlöf J, Lindskog S. Root surface texture after different scaling modalities. Scand J Dent Res. 1994; 102(3):156-60.

42. Takacs VJ, Lie T, Perala DG, Adams DF. Efficacy of 5 machining instruments in scaling of molar furcations. J Periodontol. 1993; 64(3):228-36.

43. Bergenholtz A, Babay N. Scanning electron microscopy of the root surface texture of extracted periodontally diseased teeth following various etching and chelating regimens. Int J Periodontics Restorative Dent. 1998; 18(2):171-9.

\section{About the Authors}

\section{Rodrigo Cavassim, DDS, MSc (Corresponding Author)}

Dr. Cavassim is a PhD student in periodontics, Department of Diagnostics and Surgery, School of Dentistry at Araraquara, São Paulo State University, UNESP, São Paulo, Brazil.

e-mail: rcavassim@yahoo.com.br

Fábio Renato Manzolli Leite, DDS, MSc

Dr. Leite is a PhD student in periodontics, Department of Diagnostics and Surgery, School of Dentistry at Araraquara, São Paulo State University, UNESP, São Paulo, Brazil.

e-mail: leite.fabio@gmail.com

Daniela Leal Zandim, DDS, MSc

Dr. Zandim is a PhD student in periodontics, Department of Diagnostics and Surgery, School of Dentistry at Araraquara, São Paulo State University, UNESP, São Paulo, Brazil

e-mail: danizandim@yahoo.com.br 
Andrea Abi Rached Dantas, DDS, MSc

Dr. Dantas is a PhD student in periodontics, Department of Diagnostics and Surgery, School of Dentistry at Araraquara, São Paulo State University, UNESP, São Paulo, Brazil.

e-mail: aarached@yahoo.com.br

José Eduardo Cezar Sampaio, DDS, PhD

Dr. Sampaio is an adjunct professor of periodontology in the Department of Diagnostics and Surgery, School of Dentistry at Araraquara, São Paulo State University, UNESP, São Paulo, Brazil.

e-mail: jsampaio@foar.unesp.br 